E International

What Does Improved Fuel Economy Cost Consumers and What Does it Cost Taxpayers?

Some Illustrations

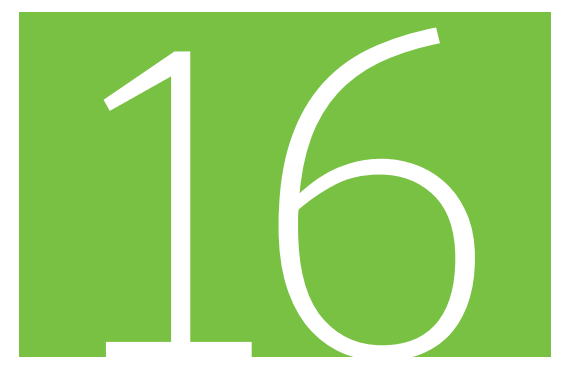

Discussion Paper 2011 • 16 
This document was produced as background for the 2011 International Transport Forum, on 25-27 May in Leipzig, Germany, on Transport for Society. The views expressed in this document do not necessarily reflect those of the member countries of the International Transport Forum.

Further information about the International Transport Forum is available at www.internationaltransportforum.org 



\section{What does improved fuel economy cost consumers and what does it cost taxpayers? Some illustrations}

Discussion Paper No. 2011-16

Kurt VAN DENDER and Philippe CRIST

Joint Transport Research Centre of the International Transport Forum and the OECD

May 2011 


\section{INTERNATIONAL TRANSPORT FORUM}

The International Transport Forum at the OECD is an intergovernmental organisation with 52 member countries. It acts as a strategic think tank with the objective of helping shape the transport policy agenda on a global level and ensuring that it contributes to economic growth, environmental protection, social inclusion and the preservation of human life and well-being. The International Transport Forum organizes an annual summit of Ministers along with leading representatives from industry, civil society and academia.

The International Transport Forum was created under a Declaration issued by the Council of Ministers of the ECMT (European Conference of Ministers of Transport) at its Ministerial Session in May 2006 under the legal authority of the Protocol of the ECMT, signed in Brussels on 17 October 1953, and legal instruments of the OECD.

The Members of the Forum are: Albania, Armenia, Australia, Austria, Azerbaijan, Belarus, Belgium, Bosnia-Herzegovina, Bulgaria, Canada, Croatia, the Czech Republic, Denmark, Estonia, Finland, France, FYROM, Georgia, Germany, Greece, Hungary, Iceland, India, Ireland, Italy, Japan, Korea, Latvia, Liechtenstein, Lithuania, Luxembourg, Malta, Mexico, Moldova, Montenegro, Netherlands, New Zealand, Norway, Poland, Portugal, Romania, Russia, Serbia, Slovakia, Slovenia, Spain, Sweden, Switzerland, Turkey, Ukraine, the United Kingdom and the United States.

The International Transport Forum's Research Centre gathers statistics and conducts cooperative research programmes addressing all modes of transport. Its findings are widely disseminated and support policymaking in Member countries as well as contributing to the annual summit.

\section{DISCUSSION PAPERS}

The International Transport Forum's Discussion Paper Series makes economic research, commissioned or carried out at its Research Centre, available to researchers and practitioners. The aim is to contribute to the understanding of the transport sector and to provide inputs to transport policy design. The Discussion Papers are not edited by the International Transport Forum and they reflect the author's opinions alone.

The Discussion Papers can be downloaded from: www.internationaltransportforum.org/itrc/DiscussionPapers/itrcpapers.html

The International Transport Forum's website is at: www.internationaltransportforum.org or further information on the Discussion Papers and other JTRC activities, please email: itf.contact@oecd.org 
TABLE OF CONTENTS

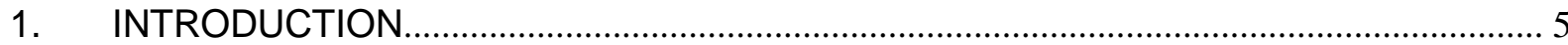

2. THE POTENTIAL IMPACT OF GREEN-GROWTH IN TRANSPORT ON FUEL-

TAX REVENUES

3. THE VALUE TO CONSUMERS AND TO TAXPAYERS OF IMPROVED FUEL

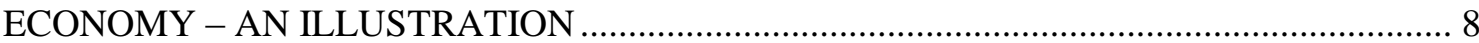

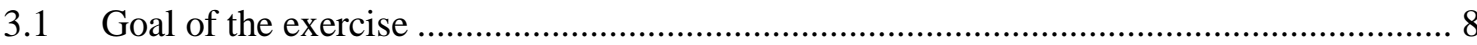

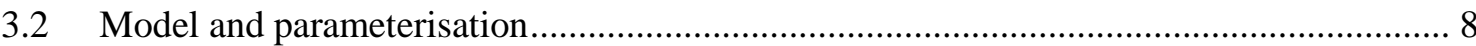

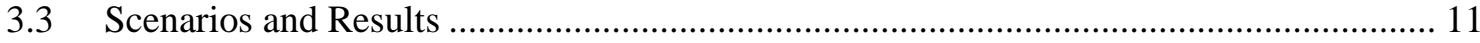

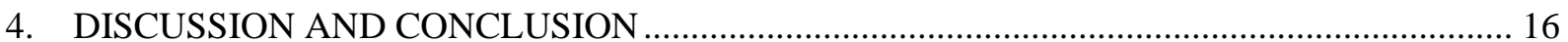

REFERENCES 



\section{INTRODUCTION}

"Green growth" is an emerging paradigm that integrates several policy aspirations, including the durability of economic activity, reduced environmental impacts, and sustained growth in highquality employment in such a way as to foster coherent, cross-sectoral policy design. Focusing on "green growth" highlights the need for governments to assess policies on their long-term economic, environmental and social impacts, recognizing that there can be synergies but also tradeoffs among the broad policy aims. As we hope to show in this paper, an examination of "green growth" policies in the transport sector provides an interesting case in point. Reducing emissions comes at a cost to consumers and taxpayers and if fuel tax revenues decline strongly it may be necessary to review the way the transport sector is taxed and contributes to aggregate tax revenue.

In Section 2 of this paper, we discuss the impact of fuel-efficiency enhancing policies in the transport sector on government fuel tax revenue by sketching the impact of fuel economy improvements and expected changes in demand on fuel consumption. In Section 3, we use a simple stylized model to illustrate how fuel economy improvements are valued by drivers, low they affect fuel tax revenues, and what this means for the appeal of such improvements from a social point of view. We also look into the potential of kilometre taxes to compensate for the erosion of the fuel tax base. Section 4 discusses the results in a policy context and offers concluding remarks.

\section{THE POTENTIAL IMPACT OF GREEN-GROWTH IN TRANSPORT ON FUEL-TAX REVENUES}

Central to the idea of "green growth" in the transport sector is that transport technologies should shift from more polluting to less polluting ones. Improved fuel economy is a central component in this shift and is generally understood to deliver a number of benefits. First, better fuel economy generate reduces the cost of driving. Therefore consumers experience welfare gains from more driving as well as reduced costs for the prevailing level of driving. Second, better fuel economy means reduced greenhouse gas emissions. Of course, this is true only to the extent that the reduced amount of emissions per unit distance driven is not is effect is not eroded by more driving. Evidence on the so-called rebound effect shows it varies with income and with fuel prices, and therefore between regions, but estimates fall in the $10-30 \%$ range, meaning that 70 to $90 \%$ of a fuel economy improvement translates into real reductions fuel use. On the other hand, some negative impacts may result as well, including increased congestion and local pollution generated by the increase in driving. Furthermore, improving fuel economy has a direct cost relating to the required technology. On balance, society is often thought to benefit from better fuel economy for light duty vehicles and improving it has been a focus of 
transport policy in many countries in recent years. But how costs compare to benefits depends on how ambitious fuel economy improvement goals are and on how they are designed. The detailed characteristics of a fuel economy policy that aims to push fuel economy levels beyond what the market produces will determine its success.

One element in the appraisal is that governments may experience an erosion of fuel tax revenue as fleet-wide fuel economy improves. For example, the recent change in CAFE fuel economy standards in the United States is expected to result in 61.6 billion gallons less fuel consumed from 2012 to $2016^{1}$ (NHTSA, 2009) after accounting for a slight increase in driving due to lower travel costs. At a constant combined Federal and State tax rate of 43 cents per gallon, this results in a drop of 26.4 billion dollars from what could have been expected under the old CAFE regime. This is not an insignificant "loss" of revenue, as it represents approximately 72\% of 2008 US Highway Trust Fund revenues (National Surface Transportation Infrastructure Financing Commission, 2009).

In order to illustrate what improvements in transport energy efficiency over the long run may mean for tax revenues from transport fuels, we used two scenarios in the IEA's MOMO mobility model $^{2}$ to assess future liquid fossil fuel demand for light-duty vehicles (LDVs - cars and light trucks). We consider scenarios for France, Japan, and the USA. Since we are interested in the potential impact to government revenues from fuel taxes if these do not change, we look only at the current tax base which for light-duty vehicles concerns essentially gasoline and diesel fuel. In both scenarios, fuel taxes are held constant at their current level, and fuel costs increase in line with the IEA World Energy Outlook projection. Light-duty vehicle travel decreases in France and Japan (by $17 \%$ and $24 \%$, respectively in 2050 compared to 2010). In the US, light-duty vehicle travel essentially stabilises at current levels. ${ }^{3}$

The baseline scenario assumes that current and expected policies are implemented and that the fleet is still dominated by internal combustion engines (gasoline and diesel). These two technologies represent $80 \%$ of total LDV stocks in the France and $70 \%$ of LDV stocks in Japan in 2050. The remainder of the LDV fleet is essentially comprised of gasoline/diesel hybrids (including plug-in hybrids), while pure electric vehicles make little penetration in the fleet by 2050. Fuel consumption of new LDVs improves along current trends (See Table 1) resulting in a $34 \%, 40 \%$ and $33 \%$ drop in LDV demand for gasoline and diesel fuel by 2050 in France, Japan and the United States, respectively.

Table 1. Percent change in average fuel consumption $(\mathrm{I} / 100 \mathrm{~km})$ for new light-duty vehicles in 2050 compared to 2010; MOMO baseline and "Blue Map" scenarios

\begin{tabular}{lcccccccc}
\hline & \multicolumn{3}{c}{ Baseline Scenario } & \multicolumn{3}{c}{ Blue-Map Scenario } \\
\hline & Gasoline & $\begin{array}{l}\text { Gasoline } \\
\text { Hybrid }\end{array}$ & Diesel & $\begin{array}{l}\text { Diesel } \\
\text { Hybrid }\end{array}$ & Gasoline & $\begin{array}{l}\text { Gasoline } \\
\text { Hybrid }\end{array}$ & Diesel & $\begin{array}{c}\text { Diesel } \\
\text { Hybrid }\end{array}$ \\
France & $-28 \%$ & $-14 \%$ & $-12 \%$ & $-9 \%$ & $-46 \%$ & $-29 \%$ & $-32 \%$ & $-17 \%$ \\
Japan & $-28 \%$ & $-16 \%$ & $-16 \%$ & $-9 \%$ & $-43 \%$ & $-38 \%$ & $-44 \%$ & $-15 \%$ \\
USA & $-32 \%$ & $-13 \%$ & $-25 \%$ & $-6 \%$ & $-29 \%$ & $-55 \%$ & $-42 \%$ & $-17 \%$ \\
\hline
\end{tabular}

1 From the "business-as-usual" projection

2 We used the October 2010 version.

3 These demand projections can be considered as low range. See ITF, 2011, Transport Outlook 2001 for some discussion and a higher range scenario. 
In the MOMO "Blue-Map" scenario, the transport sector significantly decarbonises by 2050 , consistent with a global energy use scenario that stabilises atmospheric concentrations of $\mathrm{CO} 2$ at 450 ppm. ${ }^{4}$ This scenario is characterised by strong shifts away from "traditional" internal combustion engine technologies and the projected LDV fleets in all three countries are dominated by hybrid, fuel cell and electric vehicles in 2050. At the same time, the fuel economy of new fossil-fuel consuming vehicles increases significantly as outlined in Table 1 . The resulting drop in gasoline and diesel fuel demand is significant by 2050 in all three countries - 87\%, 91\% and $89 \%$ respectfully in France, Japan and the United States. The corresponding change in fuel tax revenue is roughly in line with these decreases even when accounting for the difference in gas vs. diesel tax rates.

\section{Figure 1. Change in light-duty vehicle gasoline and diesel fuel demand from 2000-2050 under MOMO baseline and "Blue-Map"scenarios: France, Japan and the United States}

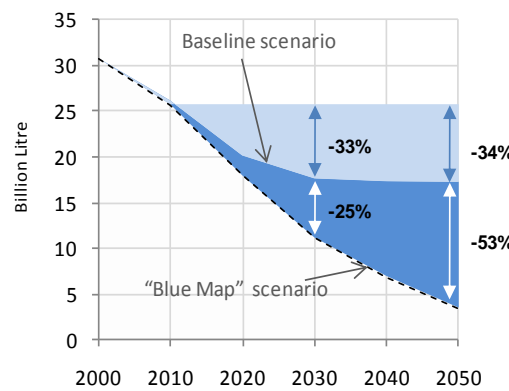

France

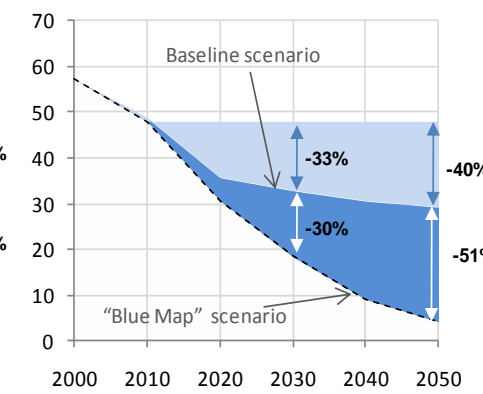

Japan

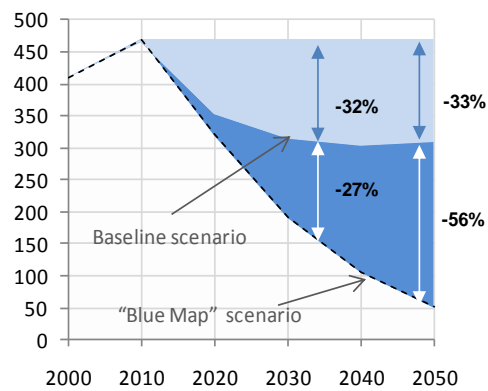

USA

The above example provides just an order of magnitude as it assumes that governments do not adapt fiscal policies in response to predictable revenue erosion, and the demand and fuel economy projections obviously are subject to high uncertainty. However, it does have the merit of highlighting the size of the potential loss in revenue, both in the baseline and the more extreme decarbonisation scenario. Further revenue loss could be expected if current policies of favourable car purchase and/or registration taxes for LDVs with low $\mathrm{CO} 2$ emissions (or high fuel economy ratings) are maintained. The cumulative drop in revenue presents a strong challenge in the baseline scenario for many countries, and the situation is untenable in the "Blue-Map" scenario, unless creative solutions are found to raise taxes at low economic costs in other ways. ${ }^{5}$ Of course, lower fuel tax receipts are just one among a range of welfare-relevant effects of improved fuel economy. The next section illustrates the overall impact of increased fuel economy on non-environment components of welfare. It does so by considering a limited

4 Under current scientific understanding, a stabilisation of atmospheric concentrations of CO2 at 450 ppm would have a $50 \%$ chance of resulting in no more than a 2 degree rise in average global temperature by 2100 .

5. The sustainability of the current fiscal structure in transport is not directly related to whether transport tax revenues are earmarked or not. Where fuel tax proceeds are hypothecated to dedicated transport funds (as is the case for the US and was the case until recently for the national portion of the Japanese fuel tax), a drop in revenue may be immediately felt, especially against a long-term trend in the rise of transport infrastructure capital and maintenance costs. In the more common case where fuel tax proceeds go directly into general government revenue, the impact of lower fuel sales will be felt more diffusely. In both cases, the shortfall must be accommodated by increased borrowing, by decreasing expenditures or by seeking a new direct or indirect funding basis for infrastructure and maintenance in a less carbon-intensive world. 
improvement in fuel economy for a currently available "average" car. As will be seen, the fuel tax component is a crucial element in the appraisal.

\section{THE VALUE TO CONSUMERS AND TO TAXPAYERS OF IMPROVED FUEL ECONOMY - AN ILLUSTRATION}

\subsection{Goal of the exercise}

This section illustrates some of the main effects that an improvement in fuel economy has on the value of the vehicle for drivers and for the Treasury. Better fuel economy means that driving becomes cheaper for any given fuel price. Consequently, drivers should be willing to invest in better fuel economy up to the point where the reduced cost of driving becomes just as large as the marginal cost of investment in fuel economy. In addition, a lower cost of driving could lead to an increased demand for driving, on the general principle that demand increases when prices fall. At the same time, to the extent that better fuel economy leads to lower fuel consumption, it leads to lower fuel tax revenues if the fuel tax does not change or does not change enough to compensate for the lower per unit revenue. Changes in the fuel tax or the introduction of a kilometre-tax could counteract this effect.

While the direction of responses to changes in fuel economy is intuitively clear, there is considerable uncertainty about their size. The purpose of this section is to sketch orders of magnitude, at the level of an "average" vehicle (not the fleet), of the main impacts of a fuel economy improvement as envisaged in the European Union regulation on $\mathrm{CO} 2$ emissions from new cars $\left(E C / 443 / 2009^{6}\right)$. We draw from literature to establish lower and upper bounds for the main impacts. The result is an indication of whether mandated fuel economy improvements are appealing from consumers' and society's point of view.

Section 3.2 presents the characteristics of the illustration, Section 3.3 provides an overview of results, and Section 3.4 discusses and concludes.

\subsection{Model and parameterisation}

Policy experiment and vehicle type

The proposed regulation in the European Union aims to reduce fleet average emissions of CO2 from $160 \mathrm{~g} / \mathrm{km}$ (in 2006) to $130 \mathrm{~g} / \mathrm{km}$ (in 2012). ${ }^{7}$ Fergusson et al. (2007) suggest that an average new vehicle emitting $160 \mathrm{~g} / \mathrm{km}$ would cost about $20,000 €$, and the technology cost of reducing emissions to $130 \mathrm{~g} / \mathrm{km}$ is between $1,000 €$ and $2,500 €$. We use these figures as guidance for retail prices, assuming that prices are close to marginal costs in the sector, a plausible assumption given strong competition in the automobile industry. Regarding the technology costs of improving fuel economy, we note that the 1,000 to $2,500 €$ range is an ex

6. http://eur-lex.europa.eu/LexUriServ/LexUriServ.do?uri=OJ:L:2009:140:0001:0015:EN:PDF

7. With a phase in that requires the most fuel efficient $65 \%$ of the fleet to meet the standard in 2012 and the full fleet to meet the standard by 2015 . 
ante estimate (see e.g. ITF-JTRC, 2008). Given a widespread view that ex post costs could be much lower, we use an informal lower bound in our discussion of results as well.

We complement the vehicle price data with additional information that roughly represents the French situation, where the modal new car is a diesel car - as will be assumed throughout our example. Data for 2009 indicate that diesel cars are driven on average 15,762km/year, compared to 9,120 for petrol cars (SOeS, 2010). Since the average diesel car of our example (it could, for example, be a Peugeot 308) is not in the class of heavily used vehicles (large families, professional use,...) we reduce reference situation usage to $12,500 \mathrm{~km} /$ year. Other data are consistent with Prud'homme (2010). ${ }^{8}$ The price of a barrel of crude oil is $75 €$ throughout ${ }^{9}$, the tax per litre of diesel is $0.512 €$, and other fuel costs equal $0.193 € /$ litre. The results are a fuel cost per kilometre of 7cents. The lifetime of the vehicle is taken to be 15 years, after which its residual value is zero or - more generally - the residual value is the same when different scenarios are compared. Future flows are discounted at $4 \%$, which can be seen as a social discount rate but plausibly also as a current private household discount rate. In any case, choosing a low rate is conservative in the sense that it tends to increase the value households put on future savings on fuel expenditures.

\section{Payback periods for investment in fuel economy}

Our analysis abstracts from external costs, focussing mainly on household and tax revenue effects (i.e. adopting a strict cost-effectiveness approach). When external costs are ignored, and as long as households discount flows over the full lifetime of the vehicle and their discount rate equals the social rate, private decisions on fuel economy coincide with the socially optimal ones. There is considerable evidence, however, that households use "payback periods" for investments in fuel economy that are far shorter than the expected lifetime of the vehicle. Survey evidence and industry rules of thumb suggest that households want to see the extra outlays for better fuel economy recovered within 2 or 3 years instead of 15 years (see ITF-JTRC, 2010a); the econometric evidence is more mixed but many studies find implicit discount rates that exceed the market-conform ones by a significant amount (see Greene, 2010a, and a recent and very detailed study by Alcott and Wozny, 2010). Given the mixed evidence we define a lower bound on payback periods of 3 years and an upper bound of 15 years.

A key question for the interpretation of the numerical results is what causes payback periods to be short, if in fact they are. One view is that short horizons are caused by "myopia", where a range of market failures lead consumers to demand quick payback. A different view is that consumer behaviour is better described by prospect theory (where loss aversion features large) than by expected utility theory, and this explains short payback periods (Greene, 2010c). Yet a different potential explanation is that short paybacks are the result of fully rational decisions that account for "hidden amenities", i.e. features of the decision process that are hidden to analysts but matter to households (see e.g. Small, 2010). For example, consumers might prefer that technological potential be used for improved comfort or performance instead of better fuel economy, and this leads to an observation of "too short paybacks" in a model that ignores amenities. Depending on what explanation matters most, the interpretation of results changes. If decisions just reflect hidden amenity values, then the short payback period is the socially relevant one and there is no market failure. But when there is myopia and loss aversion, a plausible case can be made that a correction to the short payback period is welfare increasing,

8. Furthermore, the structure of the simplest model version replicates Prud'homme's results.

9. In contrast to Prud'homme where the price rises by $6 \%$ per year. 
as the consumer would be better off for it (in an ex post sense). It is, of course, possible that observed payback periods partially reflect market failures and partially amenity values.

\section{The rebound effect}

Our example is set up to find what the consumer would be willing to pay to reduce CO2emissions of the modal diesel car from $160 \mathrm{~g} / \mathrm{km}$ to $130 \mathrm{~g} / \mathrm{km}$. Such a reduction is equivalent to an reduction of fuel intensity from $6.0 \mathrm{l} / 100 \mathrm{~km}$ to $4.9 \mathrm{l} / 100 \mathrm{~km}$, or an improvement of fuel economy from $16.6 \mathrm{~km} / \mathrm{l}$ to $20.4 \mathrm{~km} / \mathrm{l}$. Improving fuel economy makes driving cheaper and so more of it should be demanded. This response is called the rebound effect. While conceptually straightforward, finding out exactly how large the rebound effect might be is difficult. Small and Van Dender (2007a) find that the long run rebound effect in the USA between 1966 and 2001 is on average $20 \%$, in line with the average of earlier evidence. This means that a fuel economy improvement of $10 \%$ would reduce fuel consumption by only $8 \%$ because of the fuel consumption associated with the increased amount of driving. The authors emphasize, however, that the rebound effect is not a constant but depends on incomes and fuel prices, amongst other things. Considering the period between 1966 and 2001 instead of the sample average, the rebound effect is only $10 \%$, mainly because of income growth.

Apart from uncertainty surrounding the project-relevant magnitude of the rebound effect (the elasticity of the demand for driving with respect to the fuel cost of driving), there is an additional problem with using the empirical evidence on rebound effects in the context of fuel economy improvements. Nearly all econometric estimates of the rebound effect measure a response to the fuel cost of driving, which depends on the price of fuel and on fuel economy. The variation in the fuel cost of driving comes mainly from variation in the fuel price and less from changes in (slow-moving) fuel economy. The assumption that the fuel cost of driving is what matters is in line with textbook economics, but is not necessarily supported by the data. Indeed, Small and Van Dender (2007) find that when fuel prices and fuel economy are accounted for separately, their effects are not the same, and the effect of improved fuel economy on the demand for driving in fact is indistinguishable from zero. Greene (2010b) finds the same result for aggregate USA data. If true, this means there is no rebound effect associated with improved fuel economy. It is quite possible that this finding is more related to data problems than to behaviour, but behaviour could be an explanation as well. Therefore, in summary, it seems reasonable to put lower and upper bounds on the rebound effect (in a European context) of $0 \%$ and $20 \%$.

\section{The marginal cost of public funds}

Fuel consumption is taxed and fuel tax revenues are a valuable source of government revenues. This, again, is straightforward. But exactly how valuable is $1 €$ of fuel tax revenue or, more generally, transport tax revenue, to the economy? Answering this question requires recognizing that taxes (except for lump sum taxes) cause distortions in markets (i.e. deviations from the efficient allocation), and these distortions involve a cost (often called deadweight loss). Raising a Euro of public revenue hence costs the economy more than a Euro. Assuming then that total tax revenue is to stay constant ('equal yield'), the question becomes what the cost is to the economy of raising a unit of revenue through a different tax than the fuel tax. Is the distortionary cost of fuel taxes smaller or larger than that of alternative sources of taxes? While it is difficult to give a precise answer, some reasonable bounds can be determined. The most distortionary tax in advanced economies is probably the labour tax. It is also the main source of tax revenues. The marginal cost of a Euro of tax revenue raised by labour taxes is around $1.2-$ 1.5 Euro. France, since 2006, uses a value for the marginal cost of public funds of 1.3 in costbenefit analysis of transport projects (Quinet, 2010). How does the fuel tax or a kilometre tax 
compare to the labour tax as far as distortionary costs are concerned? If all fuel and all driving were used for commuting or business trips, then fuel taxes and kilometre taxes are effectively labour taxes, and equally costly. An appropriate weight for transport tax revenues in our simple analysis then would be 1 . But if, as is the case, transport is used for other purposes than commuting and business trips, taxing transport allows shifting the tax burden away from already heavily taxed labour. This is appealing as it reduces the efficiency cost associated with raising a given amount of total tax revenue. In the extreme, the weight put on transport tax revenues then should be 1.3, i.e. the cost associated with the alternative source of tax revenue (here labour taxes). Hence, in our illustration we use a lower bound on the weight of fuel and kilometre tax revenue of 1 and an upper bound of 1.3 .

\subsection{Scenarios and Results}

Table 2 summarises the assumptions on parameters, discussed in the previous section, in the reference situation and the situation with improved fuel economy. Table 3 repeats assumptions on lower and upper bounds on behavioural reactions and tax revenue weights. Table 4 shows key results for three policy scenarios.

Table 2. Main model parameters and variables

\begin{tabular}{lrr}
\hline & Reference & \multicolumn{2}{c}{$\begin{array}{l}\text { Counterfactual } \\
\text { Scenarios }\end{array}$} \\
\hline Lifetime of the car & 15 & 15 \\
Discount rate & $4 \%$ & $4 \%$ \\
Annual km driven & 12,500 & 12,$500 ;$ \\
Purchase price vehicle & 20,000 & 20,000 \\
Fuel economy $(\mathrm{km} / \mathrm{l})$ & 16.56 & 20.38 \\
Price of a barrel of oil $(€)$ & 75 & 75 \\
Specific tax on diesel $(€ / l)$ & 0.512 & 0.512 \\
Other fuel cost $(€ / l)$ & 0.193 & 0.193 \\
Kilometre tax & - & $0.008 ; 0.05$ \\
\hline
\end{tabular}

Table 3. Lower and upper bounds for model inputs

\begin{tabular}{lll}
\hline & Lower bound & Upper bound \\
Rebound effect & No rebound & $20 \%$ rebound \\
Payback period fuel economy investment & 3 years & 15 years \\
Economic value of reduced transport tax revenue & 1.3 & 1 \\
Economic value of increased transport tax revenue & 1 & 1.3 \\
\hline
\end{tabular}

In the first scenario, labelled "Reference fuel tax, no kilometre tax" CO2-emissions decline from $160 \mathrm{~g} / \mathrm{km}$ to $130 \mathrm{~g} / \mathrm{km}$. There is no other policy change. The model calculates what consumers are willing to pay for the improvement in fuel economy that drives the emission reduction. When there is no rebound effect, this willingness to pay is the net present value of reduced expenditures on fuel for the reference amount of driving (rectangle ABCD in Figure 2). When there is a rebound effect the increase in consumer surplus associated with the extra driving needs to be accounted for as well. We do this with a linear approximation (triangle CDE 
in Figure 2). The calculation of willingness to pay assumes the vehicle price does not change, so ignores technology costs. To arrive at a consumer valuation of the policy change, technology costs need to be compared with the willingness to pay. For a social valuation (that abstracts from externalities), the effect on tax revenues needs to be included. Note that the fuel tax, in this and all other scenarios, is maintained at the level of the reference situation.

The second scenario, "Reference fuel tax, revenue neutral kilometre tax", repeats the fuel economy improvement and adds a tax per kilometre of slightly less than $0.5 \mathrm{c} / \mathrm{km}$. This kilometre tax generates just enough revenue to offset the decline in diesel tax revenues triggered by the improvement in fuel economy in the situation where the rebound effect equals zero $\left.^{10}\right)$. In the third scenario, "Reference fuel tax, kilometre tax $5 \mathbf{c} / \mathbf{k m}$ ", the fuel economy improvement is accompanied by a kilometre tax of $5 \mathrm{c} / \mathrm{km}$. This level is intended to capture the order of magnitude that a kilometre tax might reach when it is intended to reflect average marginal external costs related to driving (not to fuel consumption) except for congestion (which we think inadvisable to include in an average tax). The value is in line with Small and Van Dender (2007b, table 5).

Figure 2. Effects of the three scenarios on consumer surplus

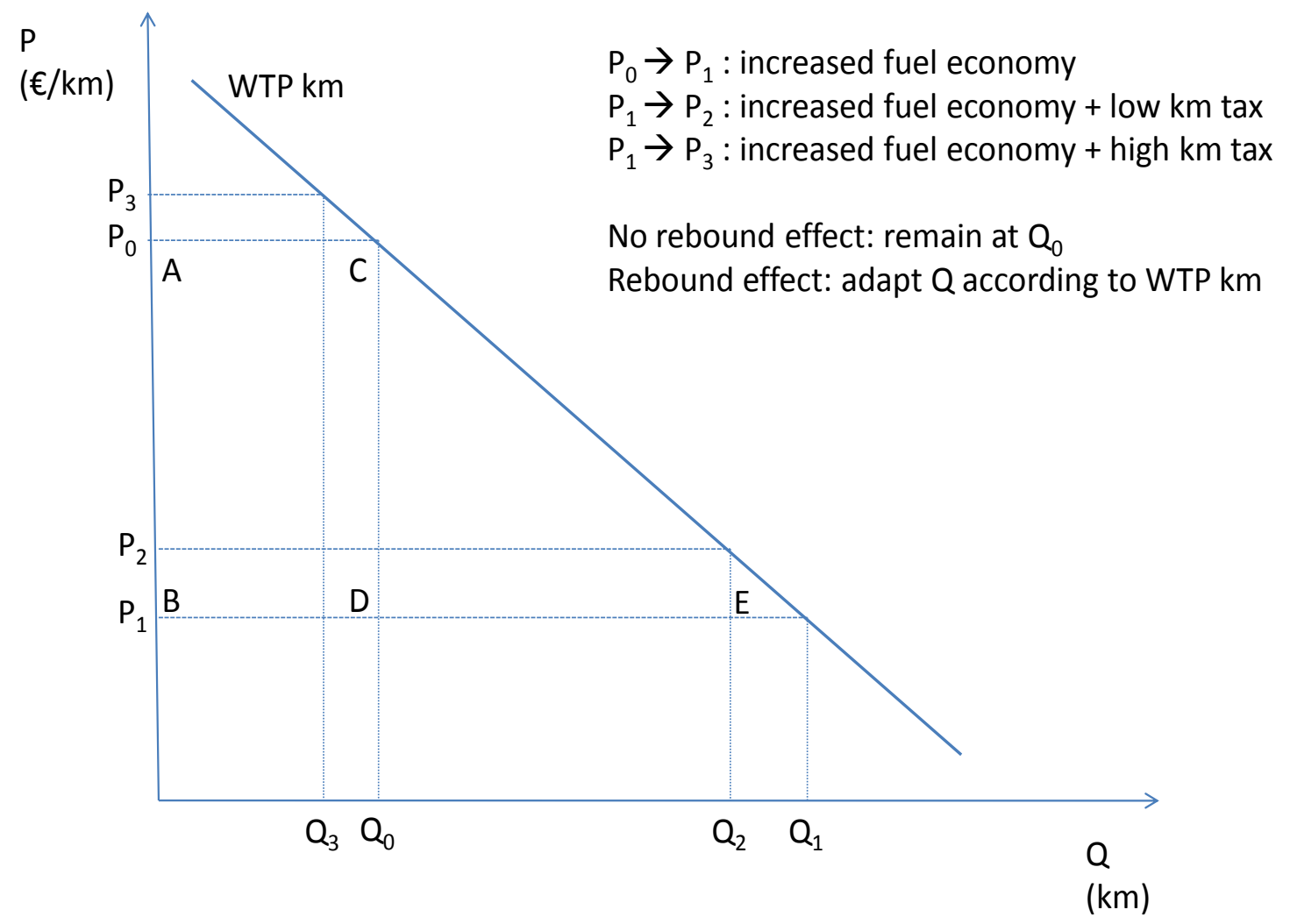

10. Note that the zero rebound effect assumption was justified above in relation to the lack of observed responses to fuel economy changes. When the cost of driving increases directly a reduction in the amount of driving is likely, even though driving is less elastic than fuel consumption. 
Table 4. Impact of reducing CO2-emissions of a $20,000 €$ diesel car from $160 \mathrm{~g} / \mathrm{km}$ to $130 \mathrm{~g} / \mathrm{km}$ on consumers' willingness to pay (WTP) and on fuel and kilometre tax revenues

\begin{tabular}{|c|c|c|c|}
\hline & & lower bound $^{a}$ & upper bound $^{\mathrm{a}}$ \\
\hline \multicolumn{4}{|c|}{ 1. Reference fuel tax, no kilometre tax } \\
\hline \multirow[t]{3}{*}{ No rebound effect } & Change in WTP for better fuel economy & $453 €$ & $1,814 €$ \\
\hline & Change in economic value of tax revenue & $-1,409 €$ & $-1,084 €$ \\
\hline & Sum & $-956 €$ & $730 €$ \\
\hline \multirow[t]{3}{*}{ Rebound effect $=20 \%{ }^{1}$} & Change in WTP for better fuel economy & $462 €$ & $1,852 €$ \\
\hline & Change in economic value of tax revenue & $-1,150 €$ & $-885 €$ \\
\hline & Sum & $-688 €$ & $967 €$ \\
\hline \multicolumn{4}{|c|}{ 2. Reference fuel tax, revenue neutral kilometre tax $(0.8 \mathrm{c} / \mathrm{km})$} \\
\hline \multirow[t]{3}{*}{ No rebound effect } & Change in WTP for better fuel economy & $182 €$ & $730 €$ \\
\hline & Change in economic value of tax revenue & $0 €$ & $0 €$ \\
\hline & Sum & $182 €$ & $730 €$ \\
\hline \multirow[t]{3}{*}{ Rebound effect $=20 \%{ }^{2}$} & Change in WTP for better fuel economy & $184 €$ & $736 €$ \\
\hline & Change in economic value of tax revenue & $91 €$ & $119 €$ \\
\hline & Sum & $275 €$ & $855 €$ \\
\hline \multicolumn{4}{|c|}{ 3. Reference fuel tax, kilometre tax $5 \mathrm{c} / \mathrm{km}$} \\
\hline \multirow[t]{3}{*}{ No rebound effect } & Change in WTP for better fuel economy & $-5,135 €$ & $-1,282 €$ \\
\hline & Change in economic value of tax revenue & $5,865 €$ & $7,625 €$ \\
\hline & Sum & $730 €$ & $6,343 €$ \\
\hline \multirow[t]{3}{*}{ Rebound effect $=20 \%{ }^{3}$} & Change in WTP for better fuel economy & $-4,926 €$ & $-1,229 €$ \\
\hline & Change in economic value of tax revenue & $4,914 €$ & $6,389 €$ \\
\hline & Sum & $-12 €$ & $5,160 €$ \\
\hline \multicolumn{2}{|c|}{ Technology cost for better fuel economy } & $1,000 €$ & $2,500 €$ \\
\hline
\end{tabular}

\footnotetext{
* Notes

a: lower bound change WTP is for 3 year payback, higher bound for 15 years

a: lower bound change tax revenue $(R)$ is for $M C P F=1$ when $d R>0$, for $M C F P=1.3$ when $d R<0$

a: upper bound change tax revenue $(R$ is for $M C P F=1.3$ when $d R>0$, for MCFP $=1$ when $d R<0$

a: lower bound technology cost is for $0 \%$ autonomous mass increase, upper bound for $2.5 \%$

1 : increase in driving $=530 \mathrm{~km}(+4.2 \%)$

2 : increase in driving $=198 \mathrm{~km}(+1.6 \%)$

3: reduction in driving $=520 \mathrm{~km}(-4.2 \%)$
}

Sources: Own calculations except technology cost taken from Fergusson et. al., 2007, Possible regulatory approaches to reducing CO2-emissions from cars, final report, IEEP, Brussels-London.

Table 4 summarises the main results from the three scenarios, distinguishing between lower and upper bounds for payback periods (see the rows on "change in WTP for better fuel economy") and for the marginal cost of public funds (rows labelled "change in economic value of tax revenue"). The lower bound on willingness to pay for better fuel economy refers to the 3 year payback period, the upper bound to 15 years of payback. What is the lower bound for the economic value of tax revenue changes depends on whether tax revenues from transport increase or decline. When they increase, the upper bound is associated with the weight of 1.3, as this is the best case from the Treasury point of view. When tax revenues decline, the weight of 1.3 refers to the lower bound, to indicate the loss of particularly valuable tax revenues (that will need to be replaced by more costly labour taxes). 
Table 4 also distinguishes the case where there is no and a $20 \%$ rebound effect. When there is an increase in the amount of driving with $20 \%$ rebound effect, this will drive up the willingness to pay for better fuel economy because it applies to more distance driven. When driving declines the opposite holds. Kilometre tax revenues increase as long as there is more driving, but what happens to fuel tax revenues depends on opposing forces (lower fuel consumption vs. more driving).

We discuss the results summarized in Table 4 by selecting worst and best case combinations of lower and upper bounds, where "best" is defined from the social point of view. We do this for every scenario.

\section{Main results per scenario}

For the "Reference fuel tax, no kilometre tax" scenario, the worst outcome occurs when the payback horizon is 3 years, the marginal cost of public funds is 1.3, and the rebound effect is zero. The social value, abstracting from technology costs and external costs, of the switch to the more efficient car is $453 €-1,409 €=-956 €$. This occurs because of the loss in highly valued tax revenues, as from the household point of view the switch is attractive in itself. With a positive rebound effect, the fuel tax base is restored to some extent (driving increases by $4.2 \%$ ), so tax revenue losses decline. The social value of the tax revenue loss is further diminished when the marginal cost of public funds is 1 instead of 1.3. And the project becomes even more attractive from the household point of view when the horizon for paybacks is 15 years instead of 3 . In the best case outcome, the social value of the project (before technology and external costs) is $1,852 €-885 €=967 €$. Taking the technology cost estimates of Fergusson et al., 2007, as guidance, this would be just about enough to justify the extra resource cost of producing the more efficient vehicle. Including the effect of reduced fuel consumption on the external costs of climate change would further add to the attractiveness of the project. Including external costs of local pollution and congestion would reduce the appeal of the project, however, as the amount of driving has gone up. The latter effect is potentially important.

What happens when the fuel economy improvement is accompanied by the introduction of a kilometre tax which is set at the level that it generates just enough revenues to compensate for lower fuel tax revenues? We have chosen tax neutrality to occur when there is no rebound effect. Consequently, the best outcome in the "Reference fuel tax, revenue neutral kilometre tax" scenario is when the rebound effect is positive, the payback horizon is 15 years, and the marginal cost of public funds is 1.3. Tax revenues now increase when driving increases (as it does by $1.6 \%$ under a positive rebound effect), and these extra revenues are worth more when the marginal cost of public funds equals 1.3. Finally, the investment is worth more to the household when it discounts over a longer horizon.

It is worth noting that in this scenario the project is appealing for all combinations of parameter values, at least before technology and external costs are accounted for. In comparison with the previous scenario, this shows that the introduction of a mileage tax can reduce or even undo the negative effects of fuel tax revenue losses associated with better fuel economy. Furthermore, the project is appealing to households as well as to the Treasury. This indicates that the revenue neutral mileage tax manages to maintain part of the consumer gain from getting better fuel economy while at the same time turning the revenue loss into a gain. It can, in that sense, be seen as an instrument to obtain both a bigger and a differently distributed total surplus. As before, accounting for technology and external costs will tend to reduce the appeal of the policy change, especially since the investment and operating costs of the new kilometre tax need to be taken into account as well. 
The revenue neutral kilometre tax, in our example, is below the level of marginal external costs associated with driving a kilometre. Scenario three, "Reference fuel tax, kilometre tax $5 \mathrm{c} / \mathrm{km}$ ", introduces a tax more in line with those costs. Driving now declines (by $4.2 \%$ ), which is good news from an external cost point of view. It is bad news from a taxation point of view as the tax base becomes smaller, but with the high tax, revenues increase spectacularly nevertheless (especially since fuel taxes remain the same as before, an assumption that becomes tenuous here as a second-best justification for current fuel tax levels should involve indirect accounting for driving-related external costs). This increase is weighs more strongly when the marginal cost of public funds is 1.3. The tax base now is largest with a zero rebound (as the rebound effect implies a decline of total driving in response to its increased cost). So the best case scenario is with a marginal cost of public funds of 1.3, a zero rebound effect, and a long horizon for paybacks.

\section{Comparing scenarios}

As can be seen from comparing sums of impacts, the scenario with the high tax on kilometres outranks the other two as long as the marginal cost of public funds is high and payback horizons are long. The first effect amplifies the interest of raising more tax revenues from transport. The second effect amplifies the interest of investing in better fuel economy from the household perspective, and undoes some of the loss in household surplus caused by the high tax on driving. Things are different with short payback periods, as in that case the revenueneutral kilometre tax strikes the best balance between maintaining tax revenues and household benefits from improved fuel economy. In general, and obviously, short payback periods strongly reduce the appeal of pushing for better fuel economy. This is in the assumption, however, that the short payback period reflects hidden amenity values (so is optimal from the household point of view).

A simpler way to compare the scenarios is to define a "middle case", in which the values for the rebound effect, the marginal cost of public funds, and the payback horizon are set halfway between the lower and upper bounds. The rebound effect then equals $10 \%$, the marginal cost of funds is 1.15, and the payback period is 9 years. This "middle case" should not be seen as representing a more probable case, as we are more inclined to view all values between the upper and lower bound as equally likely than to put a greater probability on the halfway value (and certainly do not see it as an average). Instead, the middle case is defined for ease of interpretation only, with the risk that simplification leads to a loss of information. For the middle case, the high kilometre tax scenario produces the highest net benefits: the value of tax revenue increase by $6,187 €$ and household surplus declines by $3,363 €$, leading to a net benefit of $2,824 €$. Since driving declines by $521 \mathrm{~km}(-4.2 \%)$, external costs decline as well, so that this scenario remains attractive if technology and external costs are accounted for.

In the middle case, the scenario with the revenue neutral kilometre tax remains attractive. Recalling that revenue neutrality is defined at constant mileage, the $10 \%$ rebound effect implies a slight increase in driving $(+98 \mathrm{~km}$ or $+0.8 \%)$ and a slight increase in revenue, of which the value amounts to $52 €$. Households' willingness to pay increases by $490 €$, so the total benefit before technology costs and external costs is $542 €$. With the technology costs mentioned in Table 4 and with driving-related external costs outweighing fuel-related external costs, it is unlikely that this return remains positive in a broader analysis. This holds a fortiori for the scenario with the zero kilometre tax, where the willingness to pay increases by $1,226 €$ and the value of tax revenue drops by $1,133 €$, so that the net benefit - before technology and external costs amounts to just $93 €$ (a number that, given the uncertainty on parameters, should be treated as indistinguishable from zero). 


\section{DISCUSSION AND CONCLUSION}

Whatever the merit of reducing CO2-emissions from $160 \mathrm{~g} / \mathrm{km}$ to $130 \mathrm{~g} / \mathrm{km}$, the policy by and large seems justifiable from a combined household and tax revenue perspective. If fuel economy improves without an increase in kilometre taxes (fuel taxes might work too, but were not studied here), the case for better fuel economy is contingent on exactly how expensive the technology to improve fuel economy is. When kilometre taxes are introduced, the case for better fuel economy becomes stronger, especially when the kilometre tax approaches levels that reflect external costs of driving. The downside of such high taxes on driving is distributional: they reduce consumer surplus and increase tax revenues. Raising more tax revenues is particularly attractive when the marginal cost of public funds is high.

The illustration suggests that a mandated fuel economy improvement ideally would be accompanied by a tax on driving. There is an important caveat here, in that we have assumed that kilometre taxes can be raised costlessly (more precisely, that they are not more expensive to raise than fuel taxes). This is far from straightforward, as concerns are mounting that distance-based taxes on transport are expensive to raise (see e.g. Oehry, 2010 and ITF-JTRC, 2010b). Accounting for high collection costs obviously reduces the appeal of the policy package. Furthermore, introducing comprehensive distance-based taxes is not only expensive, it is also politically difficult (as the recent Dutch experience illustrates). Assuming that the political difficulty of increasing fuel taxes can be sidestepped by introducing a substantial tax per kilometre, may border on the naive. Taking account of political constraints and collection costs, the more realistic vision seems to be that car use taxes likely will consist of fuel taxes and distance- or congestion-taxes in a limited number of densely travelled areas. While we leave the analysis of the interaction between fuel taxes, kilometre taxes, and fuel economy regulation for future work, it is worth mentioning that the very long term outlook in some countries points to a decline of aggregate distances travelled. This reinforces the problems with raising revenues from transport, as it suggests that the tax base shrinks (although the ability to pay could still increase). Should we expect that the role of the transport sector as a net contributor to overall tax revenues will decline in the long run?

Lastly, the illustration highlights the dependence of results on the payback periods that households use when deciding on how much to invest in fuel economy. Short paybacks drastically reduce the benefits of these policies. As indicated in Section 2, the key question here is whether these short payback periods reflect hidden amenities or instead some type of market failure. In the former case, the short payback is the one that matters from the social point of view, meaning that boosting fuel economy truly is less attractive. When there are market failures, making sure that decisions reflect longer paybacks is appropriate, as this now is the socially relevant case. Correcting the market failure as cheaply as possible, where costs of funds need to be accounted for, then becomes key. As we have argued elsewhere (Van Dender, 2009), fuel economy standards can very well have a role to play in that case. But the preliminary question, "hidden amenities or market failures?", needs to be settled. 


\section{REFERENCES}

Alcott H. and N. Wozny, 2010, Gasoline prices, fuel economy, and the energy paradox, Center for Energy and Environmental Policy Research Working Paper 10-003, MIT.

Fergusson et. al., 2007, Possible regulatory approaches to reducing CO2-emissions from cars, final report, IEEP, Brussels-London.

Greene D., 2010a, Why the market for new passenger cars generally undervalues fuel economy, JTRC Discussion Paper 2010-6.

Greene D.L., 2010b, Rebound 2007: analysis of U.S. light-duty vehicle travel statistics, Energy Policy (forthcoming, available online).

Greene D.L., 2010c, Uncertainty, loss aversion, and markets for energy efficiency, Energy Economics (forthcoming, available online).

Huang H., H. Lee, G. Lovellette \& J. Gomez-lbanez, 2010, Transportation Revenue Options: Infrastructure, Emissions and Congestion. Discussion Paper 2010-13/ Energy Technology Innovation Policy Series, Cambridge, Massachussetts, United States of America: Harvard Kennedy School: Belfer Center for Scince and International Affairs.

ITF-JTRC, 2008, The cost and effectiveness of policies to reduce vehicle emissions, JTRC Discussion Paper 2008-9.

ITF-JTRC, 2010a, Stimulating low-carbon vehicle technologies, JTRC Discussion Paper 201013.

ITF-JTRC, 2010b, Implementing congestion charging, JTRC Discussion Paper 2010-12.

National Surface Transportation Infrastructure Financing Commission, 2009, Paving our Way: A New Framework for Transportation Finance, Washington, DC, United States of America.

NHTSA, 2009, Corporate Average Fuel Economy for MY 2012-MY 2016; Preliminary Regulatory Impact Analysis. Washington, DC, United States of America: US Department of Transport National Highway Traffic Safety Administration

Oehry B., 2010, Critical success factors for implementing road charging systems, JTRC Discussion Paper 2010-03.

Prud'homme R., 2010, Electric vehicles: a tentative economic and environmental evaluation, paper prepared for the KOTI-ITF seminar of 25 November 2010.

Quinet E., 2010, The practice of cost-benefit analysis in transport: the case of France, JTRC Discussion Paper 2010-17. 
Small K., 2010, Energy policies for automobile transportation - a comparison using the National Energy Modeling System, Resources for the Future Backgrounder, June 2010.

Small K. and K. Van Dender, 2007a, Fuel efficiency and motor vehicle travel: the declining rebound effect, Energy Journal, 28, 1, 25-51.

Small K. and K. Van Dender, 2007b, Long-run trends in transport demand, fuel price elasticities and implications of the oil outlook for transport policy, JTRC Discussion Paper 2007-17.

SOes, 2010, Les transports en 2009 (tome 1 - le bilan de la circulation), juin 2010.

Van Dender K., 2009, Energy policy in transport and transport policy, Energy Policy (special issue), 37, 3854-3862. 
E International

International Transport Forum

2 rue André Pascal

75775 Paris Cedex 16

itf.contact@oecd.org

www.internationaltransportforum.org 